\title{
BMJ Open Barriers and determinants of asthma control in children and adolescents in Africa: a systematic review
}

\author{
Reratilwe Ephenia Mphahlele (D) , ${ }^{1}$ Omolemo Kitchin, ${ }^{2}$ R Masekela (D) ${ }^{1}$
}

To cite: Mphahlele RE, Kitchin 0, Masekela R. Barriers and determinants of asthma control in children and adolescents in Africa: a systematic review. BMJ Open 2021;11:e053100. doi:10.1136/ bmjopen-2021-053100

- Prepublication history and additional supplemental material for this paper are available online. To view these files, please visit the journal online (http://dx.doi.org/10.1136/ bmjopen-2021-053100).

Received 05 May 2021 Accepted 11 0ctober 2021

D Check for updates

(c) Author(s) (or their employer(s)) 2021. Re-use permitted under CC BY-NC. No commercial re-use. See rights and permissions. Published by BMJ.

${ }^{1}$ Department of Paediatrics and Child Health, University of KwaZulu-Natal Nelson R Mandela School of Medicine, Durban, South Africa

${ }^{2}$ Department of Paediatrics and Child Health, University of Pretoria, Pretoria, South Africa

Correspondence to

Dr Reratilwe Ephenia Mphahlele; mphahleler@ukzn.ac.za

\section{ABSTRACT}

Objective To identify reasons for poor asthma control in African children and adolescents.

Design Systematic review

Data sources PubMed, Scopus, CINHAL, PsycINF0, MEDLINE and Web of Science databases were systematically searched up to 31 May 2020. Hand searching was done on Sabinet, African Journal online and Google Scholar.

Eligibility criteria Studies identifying barriers to asthma control, where asthma control was assessed by the validated Asthma Control Test/Child Asthma Control Test and/or Asthma Control Questionnaire were included. Data extraction and synthesis Two reviewers independently selected studies for inclusion with disagreements resolved by a research team discussion, including a third reviewer. Data were extracted using the Cochrane Effective Practice and Organization of Care data collection form. The quality of the included studies was assessed using the modified Newcastle-0ttawa quality assessment scale. Identified barriers were reported in a thematic narrative synthesis.

Primary outcomes Poorly controlled asthma and associated factors.

Results From 914 records, three studies conducted between 2014 and 2019 in Nigeria, Uganda and South Africa met the inclusion criteria. A total of 883 children aged 4-19 years were analysed. Older age, concurrent allergy and city-dwelling significantly impacted asthma control. Few children with asthma symptoms in the community had ever used inhaled corticosteroids (6.7\%) and identified reasons included lack of asthma diagnosis (38.8\%) and no prescribed treatment (47.6\%).

Conclusion Asthma control in African children is impacted by age, allergy, urbanisation and lack of access to asthma diagnosis and treatment. More studies focusing on identifying barriers to asthma control in Africa are needed. PROSPERO Registration no: CRD42020196755)

\section{INTRODUCTION}

Asthma is a chronic non-communicable respiratory disease. According to the 2018 Global Asthma Report, asthma affects over 340 million people worldwide, the majority of whom reside in low-income and middleincome countries (LMICs). ${ }^{1}$ In contrast to many high-income countries (HICs), the prevalence of asthma is steadily increasing

\section{Strength and limitations of this study}

This systematic review highlights the paucity of studies on barriers and determinants of asthma control in Africa.

- The sufficiently validated Asthma Control Test/Child Asthma Control Test was used to assess asthma outcomes and identify barriers to asthma control.

- Barriers to asthma control reported in this study contribute to, and match those described in the literature on paediatric asthma.

- A limitation of this study is that the heterogeneity of the studies precluded a meta-analysis.

in LMICs, particularly in Africa. ${ }^{1}$ The latest systematic review on asthma prevalence in Africa shows that compared with 74 million in 1990, by 2010, asthma affected 119 million of the total population. Of concern, nearly half of these asthma cases were children under 15 years. ${ }^{2}$ Countries with the highest childhood asthma prevalence in Africa, South Africa $(20.3 \%)$, Congo (19.9\%) and Ivory Coast $(19.3 \%)$, are also regions with increasing urbanisation rates. ${ }^{3}{ }^{4}$ Factors associated with urbanisation including poverty, poor air quality and lifestyle and dietary changes may drive the rising asthma rate and impact asthma control. ${ }^{5}$ However, in this setting, access to asthma healthcare and diagnosis as well as asthma research and research infrastructure remains lacking. ${ }^{6-9}$

The most commonly used validated tools for asthma control assessment are the composite score instruments: Asthma Control Test (ACT), Child Asthma Control Test (cACT) and the Asthma Control Questionnaire (ACQ). ${ }^{10}$ The ACT and ACQ provide a quantitative assessment of asthma control and have been designated as core measures by the National Institutes of Health (NIH) for clinical research and observational studies. ${ }^{10}{ }^{11}$ ACT and ACQ are simple methods that can help quantify the impact of barriers on asthma control, ${ }^{12}$ which may not 
be comparable between HICs and LMICs. ${ }^{13}$ This review was conducted to collate data on reported barriers to asthma control in children and adolescents in Africa.

\section{METHODS}

The systematic review is registered with PROSPERO (registration no: CRD42020196755). We used the Population, Exposure, Comparator and Outcomes (PECO) acronym to aid with the systematic search. The Preferred Reporting Items for Systematic Reviews and MetaAnalyses (PRISMA) reporting standards were followed. ${ }^{14}$ The Synthesis Without Meta-Analysis reporting items guideline was used in conjunction with the PRISMA. ${ }^{15}$

\section{Search strategy}

The following databases were searched: PubMed, Scopus, CINHAL, PsycINFO, MEDLINE and Web of Science. The search methodology for all the databases is provided in the supplementary material (online supplemental table 1). Hand searching of the following databases was also conducted: Sabinet, African Journal online and Google Scholar. Only scientific articles written in English with date restrictions from 1 January 2000 to 31 May 2020 were included.

The search strategy was structured to include terms for 'Child', 'Asthma', 'Barriers', 'Asthma Control Test', 'Africa' and/or variations of these.

\section{Selection of studies}

Studies identified from searching electronic databases were combined and duplicates were removed. Two reviewers (REM, OK) independently screened references using a three-stage review of title and abstract, followed by a full-text review of included studies. The full text of potentially eligible studies was screened against the review criteria and potential articles identified. At each stage, disagreements were resolved by a team discussion with a third reviewer (RM).

\section{Inclusion and exclusion criteria}

The study's focus was to identify barriers associated with poor asthma control in African children and adolescents with doctor-diagnosed/suspected asthma, where the validated ACT/CACT or ACQ tool was used to assess asthma control. The population included children between the ages of 6 and 18 years. Studies were included with broader age ranges if children aged $6-18$ years were reported separately, or if $>50 \%$ of the population were children within this age range.

Studies published from January 2000 to May 2020 were included to ensure the encompassing of all data since validation of the ACT and ACQ. Clinical trials assessing pharmaceutical treatment and diagnostic accuracy of tools were excluded. Grey literature from experts in the field, conference abstracts or unpublished material were also excluded (table 1).

\section{Data extraction}

The full texts of all studies found to be relevant and meeting the inclusion criteria were retained for data extraction and final synthesis. Data including study design, setting, population, authorship and statistical analysis was extracted using a standardised data extraction form modified from the Cochrane Effective Practice and Organization of Care data collection form. ${ }^{16}$ The authors were contacted where clarification was required, and data were missing. The selection process was summarised using a PRISMA flow diagram (figure 1).

\section{Quality assessment}

The included studies' quality was assessed using the modified Newcastle-Ottawa Scale for cohort, case studies and cross-sectional studies ${ }^{17}$ (online supplemental table 2).

\section{Data analysis and synthesis}

We anticipated that the population and statistical analysis heterogeneity of the studies would preclude a formal meta-analysis. We, therefore, grouped into themes asthma control barriers corresponding to literature; patient, environmental, healthcare/doctor-related factors and comorbidities. ${ }^{12}{ }^{13}$ (online supplemental table 3). Statistical analyses were performed using MedCalc-Software, Ostend, Belgium; http://www.medcalc.org; $2018 .{ }^{18}$

\section{Patient and public involvement}

Patients and the public were not involved in the study design or conduction of the study.

\section{RESULTS}

\section{Search results}

There were 914 articles identified: 863 articles through electronic database searching (EBSCO host=27, PubMed=136, Web of Science $=97$, Scopus $=603$ ) and an additional 51 articles through hand searching (Google scholar=23, Sabinet=12, AJOL=16). The total number of articles found after duplicates were removed was 498 . Of the 498 articles screened, 484 were excluded as they were not appropriate or did not relate to the study. The remaining 14 full articles were assessed for eligibility, and 11 articles were excluded for the following reasons: wrong age group $=2$, did not use $\mathrm{ACT} / \mathrm{ACQ}=2$, not original research $=2$, assessed impact rather than barriers of poor asthma control=5. Three studies met the inclusion criteria (figure 1).

\section{Characteristics of the studies}

All three studies conducted in Nigeria, South Africa and Uganda ${ }^{19-21}$ were cross-sectional; two hospital-based and one community-based. The sample size was smaller for hospital-based studies with 207 and 115 participants in Nigeria $^{19}$ and South Africa, ${ }^{20}$ respectively, compared with the community-based study of 561 participants in Uganda. ${ }^{21}$ Publication dates ranged from 2014 to 2019. The ages of participants ranged from 4 to 19 years. Asthma diagnosis was based on doctor diagnosis ${ }^{19} 20$ guided by 
Table 1 Criteria for the search and rules devised to facilitate inclusion/exclusion criteria

\begin{tabular}{|c|c|c|}
\hline Search strategy & Definition & Rules \\
\hline Population & $\begin{array}{l}\text { Children and adolescents between ages } 6 \text { and } 18 \text { years } \\
\text { with a doctor diagnosis or a baseline prescription for } \\
\text { asthma treatment or presumed diagnosis of asthma based } \\
\text { on a history of recurrent wheeze. }\end{array}$ & $\begin{array}{l}\text { Included: } \\
\text { Studies with broader ranges of ages if } \\
\text { children aged } 6-18 \text { were reported separately } \\
\text { or if }>50 \% \text { of the population were children } \\
\text { within this age range. } \\
\text { Excluded: } \\
\text { Studies in adults ( }>18 \text { years). }\end{array}$ \\
\hline $\begin{array}{l}\text { Comparison (if } \\
\text { applicable) }\end{array}$ & $\begin{array}{l}\text { Usual care in people of the same age with well-controlled } \\
\text { asthma }\end{array}$ & \\
\hline Outcome & Asthma control measured using ACT/cACT and/or ACQ & $\begin{array}{l}\text { Excluded: } \\
\text { Studies using tools for measuring asthma } \\
\text { control other than ACT/CACT and/or ACQ }\end{array}$ \\
\hline Timeframe & 20 years between January 2000 and May 2020 & $\begin{array}{l}\text { Excluded: } \\
\text { Studies conducted before January } 2000 \text { and } \\
\text { after May } 2020\end{array}$ \\
\hline
\end{tabular}

ACQ, Asthma Control Questionnaire; ACT, Asthma Control Test; cACT, Child Asthma Control Test.

the Global Initiative on Asthma (GINA), ${ }^{19}$ and symptom screening by the International Study of Asthma and Allergies in Childhood questionnaire. ${ }^{21}$ One study adjusted for age, gender and concurrent allergy, ${ }^{21}$ while the rest did not report adjusting for potential confounders, reducing their quality score ${ }^{1920}$ (online supplemental table 2). To recruit participants, two of the hospital-based studies used consecutive enrolment from a group of children attending asthma clinic. ${ }^{19} 20$ The community-based study derived participants from a large case-control study investigating risk factors of asthma in school going children $^{2122}$ (table 2).

\section{Assessment of asthma control}

All the studies measured asthma control using ACT and cACT. Scores were based on the cut-off point of $>19$ for controlled asthma and $\leq 19$ for uncontrolled asthma. The prevalence of uncontrolled asthma in the Nigeria,
South Africa and Uganda was $30.9 \%, 44.3 \%$ and $44.5 \%$ respectively.

\section{Thematic synthesis}

\section{Patient-related factors}

Age

Two studies assessed the impact of age on asthma control. The large community-based study showed that older age (13-17years) was significantly associated with poorer asthma control (adjusted regression coefficient $(95 \%$ confidence interval), p-value: $(-1.07$ (-1.20 to -0.94$)$, $\mathrm{p}<0.0001) .^{21}$ The exception was a small clinic cohort of moderate quality, which showed no association. ${ }^{20}$

\section{Gender}

Two of the studies ${ }^{20} 21$ that examined gender showed no significant association with asthma control. 


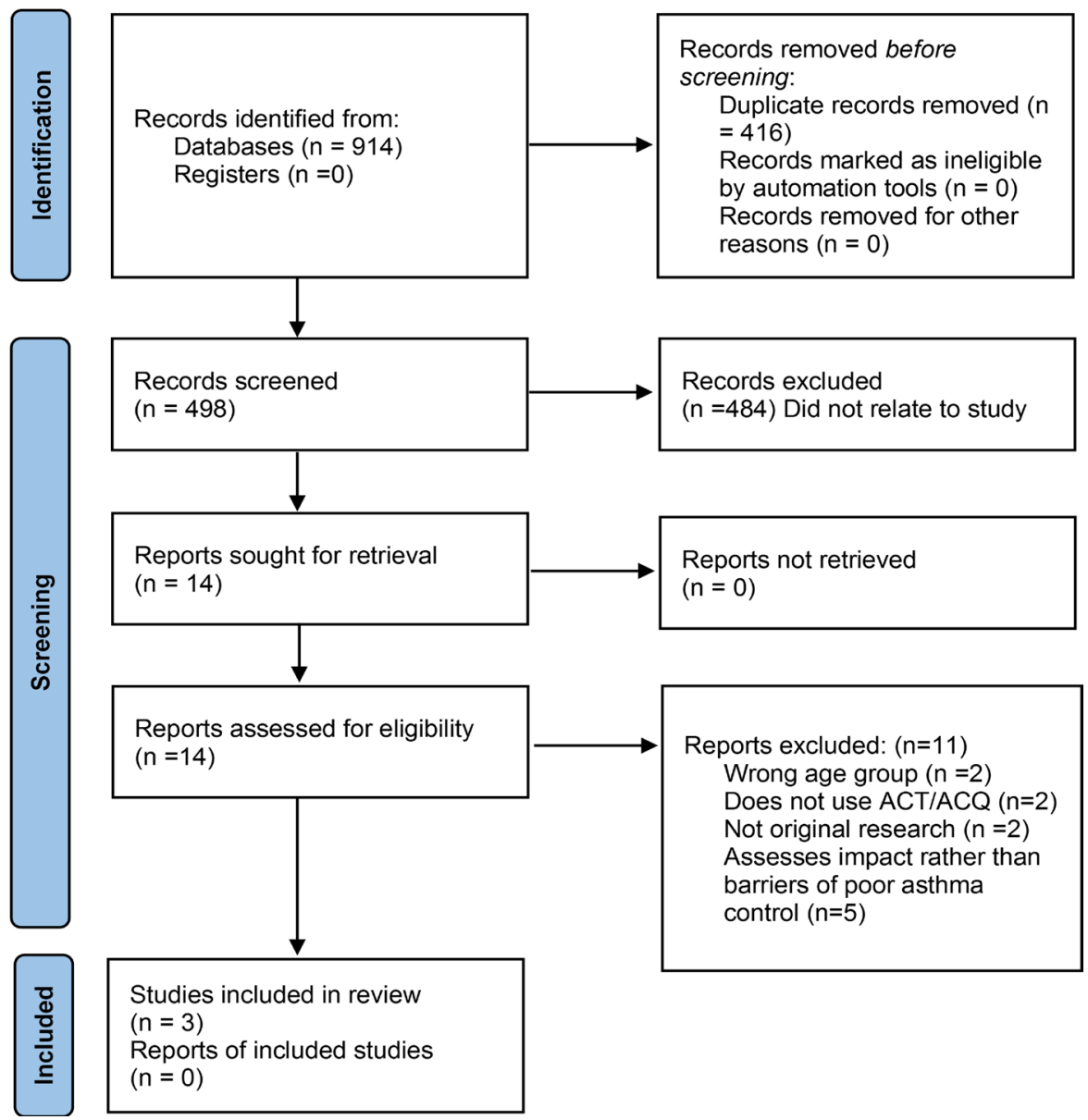

Figure 1 Study eligibility chart according to Preferred Reporting Items for Systematic Reviews and Meta-Analyses criteria. ACQ, Asthma Control Questionnaire; ACT, Asthma Control Test.

\section{Asthma medication use}

Two studies ${ }^{20} 21$ examined the use and compliance of asthma medication. The study among school-going children $^{21}$ showed that the majority $(73 \%)$ had never used inhaled asthma medications. Additionally, regular use of inhaled asthma medication in the last 12 months was inadequate for salbutamol (18.1\%) and corticosteroid (6.7\%) even though the majority $(55.8 \%)$ had a doctor diagnosis of asthma. Although not significant, in the same cohort, children with poorly controlled asthma preferred regular use of (salbutamol and prednisone) tablets rather than inhaled salbutamol and corticosteroids. ${ }^{21}$ Conversely, in the cohort of children attending asthma clinic, ${ }^{20}$ good adherence to medications was seen in $82.6 \%$ of patients. In these doctor-diagnosed children, asthma control was significantly associated with good adherence to medication, where $37.9 \%$ and $62.1 \%$ of patients had uncontrolled asthma and controlled asthma, respectively $\left(\chi^{2}=0.217, p=0.002\right){ }^{20}$

\section{Ethnicity}

There was no significant association between asthma control and ethnicity $\left(\chi^{2}=3.22, p=0.359\right)$ in Black-African, Caucasian, mixed-ethnicity and Indian participants in South Africa. ${ }^{20}$

\section{Environmental related factors}

Two studies conducted in Uganda ${ }^{21}$ and Nigeria ${ }^{19}$ examined the effects of rural versus urban domicile on asthma control. The school-based Ugandan cohort showed that city residence in early life was associated with poor asthma control $(-1.99$ (-3.69 to -0.29$), \mathrm{p}=0.02) .{ }^{21}$ In contrast the clinic-based cohort in Nigeria showed, although without significance, that within the rural community, more children with current allergies had better control of their asthma $(85.7 \%)$ when compared with their urban counterparts $(66.7 \%)$. Interestingly, the children who lived in rural areas without concurrent allergy had poorly controlled asthma (50.0\%) compared with their urban counterparts (28.3\%), Fisher's exact test $=2.076, \mathrm{p}=0.17$, although this too was not significant. ${ }^{19}$

All three included studies considered the presence of asthma triggers in their participants' environments, but only the South African study examined these triggers in relation to asthma control. Common triggers included dust, cold air, physical exercise, fumes or air pollution, pollen, pets, smoking and biomass fuels (figure 2). In the South African cohort, home circumstances including dust, cockroach, carpet, pets, toys in bed and smoking were not found to be associated with asthma control. ${ }^{20}$ The use of biomass fuel was uncommon in South Africa 


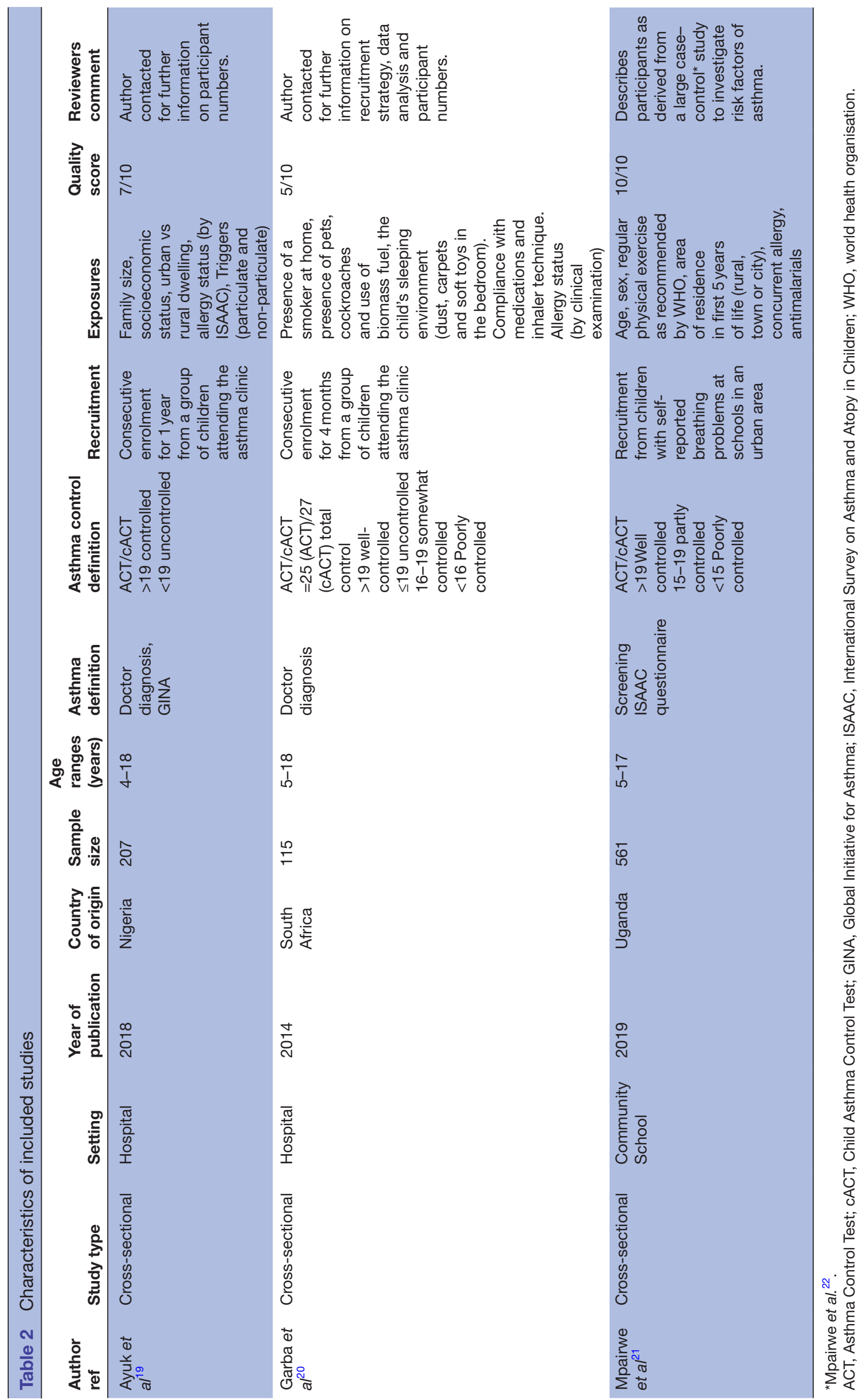




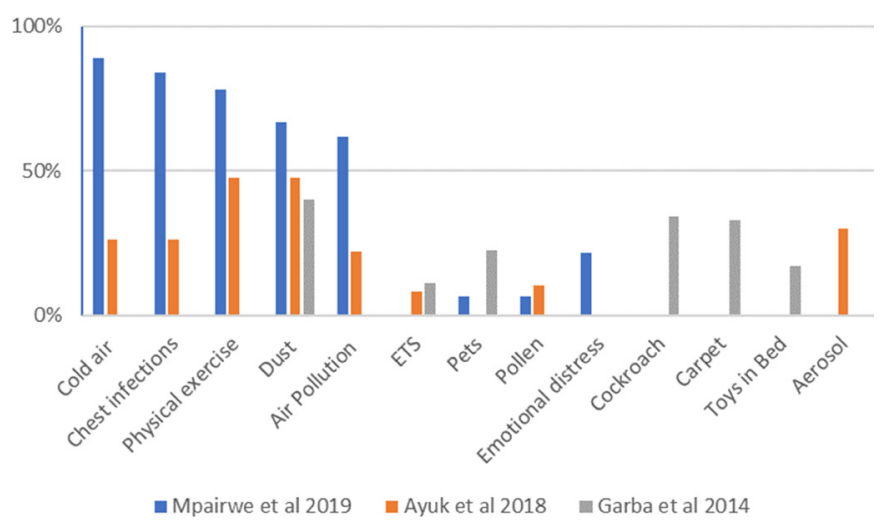

Figure 2 Prevalence of asthma triggers among study participants across African studies using the Asthma Control Test/Childhood Asthma Control Test to identify asthma control barriers. ETS, environmental tobacco smoke.

$(6.1 \%)$ compared with Nigeria $(22.1 \%)$ and was not found to be significantly associated with asthma control $\left(\chi^{2}=6.202, p=0.185\right) .^{19}{ }^{20}$

\section{Healthcare and doctor-related factors}

Only the field-based study in Uganda, reported the impact of healthcare-seeking behaviour on asthma control. In 553 children who reported treating their asthma in the last year, 26.8\% reported having ever used inhaled asthma medications, and a similar proportion, 29.7\% reported having ever used herbal remedies for asthma management. On enquiry about previous asthma assessments and follow-up, $73(13.2 \%)$ visited a health facility to monitor their asthma, $45(8.2 \%)$ children had ever had a lung function test; $2(0.4 \%)$ had ever used a peak flow metre as an asthma monitoring tool at home, and only 3 $(0.5 \%)$ had a personal written asthma action plan. ${ }^{21}$ The reason for having never used inhaled asthma medication was investigated in 405 children and included inhaled asthma medications had never been prescribed for them $(47.6 \%)$, never been diagnosed $(38.8 \%)$, high cost of inhalers $(4.5 \%)$, fear of side effects of inhalers $(4.5 \%)$, alternative treatment with salbutamol or steroid tablets $(1.4 \%)$ and non-medicinal treatment, that is, wrapping up in warm clothes and resting. ${ }^{21}$

\section{Comorbidities}

All three studies assessed children for allergic rhinitis, but only two ${ }^{192}$ in relation to asthma control. In the larger powered community-based study, ${ }^{21}$ children with concurrent allergic rhinitis were more likely to have lower asthma control scores $(-1.33$ ( -2.28 to -0.38$), \mathrm{p}=0.006)$, whereas no significant association was found between atopy and asthma control in the small cohort clinic-based study. ${ }^{19}$ However, in the latter study, children with current allergy had more emergency hospital visits due to asthma exacerbations $\left(\chi^{2}=10.09\right.$ (df: 1$) \mathrm{p}=0.002$; Spearman's $\mathrm{R}=0.22$, $\mathrm{p}=0.001){ }^{19}$

\section{DISCUSSION}

Older age, concurrent allergic rhinitis and early life urban residence are barriers similar to HICs and significantly impact asthma control in African children. Access to healthcare and appropriate asthma medication remains limited, with a minority of children with asthma symptoms ever having used inhaled corticosteroids (ICS).

\section{Older age}

Mpairwe $e t a l^{22}$ found adolescents in Uganda have inadequate asthma control and outcomes. Similarly, the age group 12-17years was more predictive of exacerbations than other age groups in a European cohort study using the General Practice Research Database. ${ }^{23}$ One reason for this can be explained by adolescent studies that show poor adherence compared with other age groups. ${ }^{24}$ Social stigma, forgetfulness and poor understanding of medication play a significant role in adherence and warrant further exploration..$^{25} 26$

\section{Concurrent allergic rhinitis}

The Ugandan and Nigerian studies found that children with allergic rhinitis (AR) had less well-controlled asthma and were more likely to be hospitalised. Similarly, in a large UK retrospective cohort of 9522 children with asthma, the presence of AR significantly increased the likelihood of physician visits and more than doubled the likelihood of hospitalisation. Furthermore, drug use and costs were significantly higher among children with asthma and concurrent AR. ${ }^{27}$ Active search and recognition of AR when assessing children remain critical in comprehensive asthma management.

\section{Rural versus urban residence}

Studies in Africa show a decreasing gradient in asthma prevalence between urban and rural areas. ${ }^{28}{ }^{29}$ In this context, biomass fuel exposure remains a significant contributor to inflammatory lung diseases, including asthma and chronic obstructive pulmonary disease ${ }^{3031} \mathrm{Few}$ studies in Africa have compared asthma control between rural and urban areas. ${ }^{19} 213233$ Urban residence was significantly associated with poorly controlled asthma in Uganda, where asthma risk among schoolchildren ${ }^{21}$ was three times higher in children who in early life resided in cities rather than rural areas. ${ }^{22}$ Similarly, rural to urban migration appears to be an important determinant of the increasing prevalence of wheeze among schoolgoing children in Latin American cities. ${ }^{34}{ }^{35}$ Increasing asthma rates in urban settings could be related to over-crowding, reduction of exercise, poorer air quality and changes in lifestyle and diets.

\section{Access to diagnosis and healthcare}

Six out of 10 children attending healthcare institutions have good asthma control, while a similar number of undiagnosed children in the community have poorly controlled asthma. ${ }^{19-21}$ Even after a diagnosis of asthma, ICS use is limited in communities ${ }^{2136}$ compared with clinic patients ${ }^{20}$ who once diagnosed, have significantly better 
asthma control. The preference of tablets (salbutamol and corticosteroids) over ICS may largely be explained by their quick relief and ease of administration combined with underlying suboptimal knowledge and asthma medications cost. ${ }^{36}$ Furthermore, traditional healers remain integral to medical care in communities due to local cultural practices and beliefs. There is a need to communicate asthma management strategies to communities in a culturally sensitive manner. ${ }^{32} 37$ Triggers including dust, air pollution, pollen, pets and smoking common across the globe, indicate the feasibility of a global checklist and the necessity of avoidance education. ${ }^{38}$

\section{Strengths and limitations}

We may not have identified all significant barriers that impact asthma control as other asthma control tools, that is, GINA and National Asthma Education Programme, were excluded because they are not as sufficiently validated as the ACT and ACQ. ${ }^{10}$ Nevertheless, we identified variables in each group classification for poor asthma control in current literature. ${ }^{13}$ Our wide-ranging search strategy found no non-English articles requiring exclusion. The studies' heterogeneity in terms of outcome analysis and population precluded a meta-analysis; therefore, we reported all the factors within the emerging themes.

\section{Implications for clinical practice, healthcare systems and policymakers}

Strategies that improve medication access, including initiatives like the WHO Essential Medicines List, low-cost equipment like plastic spacers ${ }^{39}$ and implementing culturally appropriate educational programmes for healthcare workers and the public, remain vital. ${ }^{4041}$

\section{Implications for future research}

Studies beyond healthcare institutions that include communities in identifying barriers and their impact on asthma control are needed in African children.

\section{CONCLUSION}

Asthma control barriers requiring focus in Africa are lack of accurate diagnosis, limited access to inhaled therapy, lack of asthma knowledge and poor air quality. Better education and advocacy through community-based public interventions are needed to improve African children's asthma control and outcomes.

Acknowledgements We thank Drs Vuyokazi Ntlantsana, Dickens Akena and Desmond Kuupiel for their advice in preparing this report.

Contributors REM, OK and RM designed the study and the search strategy. REM performed the literature search. REM, OK and RM performed the screening. REM performed the data extraction and analysis. REM, OK and RM interpreted the results. REM wrote the manuscript. All authors reviewed and approved the final version of the manuscript. RM is the study guarantor.

Funding The authors have not declared a specific grant for this research from any funding agency in the public, commercial or not-for-profit sectors.

Competing interests None declared.

Patient consent for publication Not applicable.
Provenance and peer review Not commissioned; externally peer reviewed.

Data availability statement All data relevant to the study are included in the article or uploaded as supplementary information.

Supplemental material This content has been supplied by the author(s). It has not been vetted by BMJ Publishing Group Limited (BMJ) and may not have been peer-reviewed. Any opinions or recommendations discussed are solely those of the author(s) and are not endorsed by BMJ. BMJ disclaims all liability and responsibility arising from any reliance placed on the content. Where the content includes any translated material, BMJ does not warrant the accuracy and reliability of the translations (including but not limited to local regulations, clinical guidelines, terminology, drug names and drug dosages), and is not responsible for any error and/or omissions arising from translation and adaptation or otherwise.

Open access This is an open access article distributed in accordance with the Creative Commons Attribution Non Commercial (CC BY-NC 4.0) license, which permits others to distribute, remix, adapt, build upon this work non-commercially, and license their derivative works on different terms, provided the original work is properly cited, appropriate credit is given, any changes made indicated, and the use is non-commercial. See: http://creativecommons.org/licenses/by-nc/4.0/.

\section{ORCID iDs}

Reratilwe Ephenia Mphahlele http://orcid.org/0000-0002-3348-9004

R Masekela http://orcid.org/0000-0002-2006-1201

\section{REFERENCES}

1 The Global Asthma Network.org [internet]. The global asthma report 2018: global asthma network, 2018. Available: http://www. globalasthmanetwork.org/

2 Adeloye D, Chan KY, Rudan I, et al. An estimate of asthma prevalence in Africa: a systematic analysis. Croat Med $J$ 2013;54:519-31.

3 Ait-Khaled N, Odhiambo J, Pearce N, et al. Prevalence of symptoms of asthma, rhinitis and eczema in 13- to 14-year-old children in Africa: the International study of asthma and allergies in childhood phase III. Allergy 2007;62:247-58.

4 United Nations, Department for Economic and Social Affairs, Population Division org [internet]. World urbanisation prospects 2018: highlights (ST/ESA/SER.A/421), 2019. Available: https://population. un.org/wup/Publications/

5 Nicolaou N, Siddique N, Custovic A. Allergic disease in urban and rural populations: increasing prevalence with increasing urbanization. Allergy 2005;60:1357-60.

6 Ehrlich RI, Jordaan E, du Toit D, et al. Underrecognition and undertreatment of asthma in Cape town primary school children. $S$ Afr Med J 1998;88:986-94.

7 Ayuk A, lloh K, Obumneme-Anyim I. Practice of asthma management among doctors in south-east Nigeria. Afr $J$ Respir Med 2010;6:14-17.

8 Masekela R, Zurba L, Gray D. Dealing with access to spirometry in Africa: a commentary on challenges and solutions. Int J Environ Res Public Health 2019;16:62.

9 Musafiri S, Joos G, Van Meerbeeck JP. Asthma, atopy and COPD in sub-Saharan countries: the challenges. East Afr J Public Health 2011;8:161-3.

10 Schatz M, Sorkness CA, Li JT, et al. Asthma control test: reliability, validity, and responsiveness in patients not previously followed by asthma specialists. J Allergy Clin Immunol 2006;117:549-56.

11 Cloutier MM, Schatz M, Castro M, et al. Asthma outcomes: composite scores of asthma control. J Allergy Clin Immunol 2012;129:S24-33.

12 Braido F. Failure in asthma control: reasons and consequences. Scientifica 2013;2013:1-15.

13 Green RJ. Barriers to optimal control of asthma and allergic rhinitis in South Africa. Current Allergy \& Clinical Immunology 2010;23:8-11.

14 Page MJ, Moher D, Bossuyt PM, et al. PRISMA 2020 explanation and elaboration: updated guidance and exemplars for reporting systematic reviews. BMJ 2021;372:n160.

15 Campbell M, McKenzie JE, Sowden A, et al. Synthesis without meta-analysis (swim) in systematic reviews: reporting guideline. BMJ 2020;368:16890.

16 Epoc.cochran.org [internet], Effective Practice and Organisation of Care (EPOC). EPOC resources for review authors. Cochrane, 2017. Available: https://epoc.cochrane.org/resources/epoc-resourcesreview-authors

17 Modesti PA, Reboldi G, Cappuccio FP, et al. Panethnic differences in blood pressure in Europe: a systematic review and meta-analysis. PLoS One 2016;11:e0147601. 
18 Schoonjans F, Zalata A, Depuydt CE, et al. MedCalc: a new computer program for medical statistics. Comput Methods Programs Biomed 1995;48:257-62.

19 Ayuk AC, Eze JN, Edelu BO, et al. The prevalence of allergic diseases among children with asthma: what is the impact on asthma control in South East Nigeria? Niger J Clin Pract 2018;21:632-8.

20 Garba B, Ballot D, White D. Home circumstances and asthma control in Johannesburg children. Current Allergy \& Clinical Immunology 2014;27:182-9.

21 Mpairwe $\mathrm{H}$, Tumwesige $\mathrm{P}$, Namutebi $\mathrm{M}$, et al. Asthma control and management among schoolchildren in urban Uganda: results from a cross-sectional study. Wellcome Open Res 2019;4:168.

22 Mpairwe H, Namutebi M, Nkurunungi G, et al. Risk factors for asthma among schoolchildren who participated in a case-control study in urban Uganda. Elife 2019;8:e49496.

23 O'Connor RD, Bleecker ER, Long A, et al. Subacute lack of asthma control and acute asthma exacerbation history as predictors of subsequent acute asthma exacerbations: evidence from managed care data. J Asthma 2010;47:422-8.

24 Kaplan A, Price D. Treatment adherence in adolescents with asthma J Asthma Allergy 2020;13:39-49.

25 De Simoni A, Horne R, Fleming L, et al. What do adolescents with asthma really think about adherence to inhalers? insights from a qualitative analysis of a UK online forum. BMJ Open 2017; 7:e015245.

26 Harris K, Mosler G, Williams SA, et al. Asthma control in London secondary school children. J Asthma 2017;54:1033-40.

27 Thomas M, Kocevar VS, Zhang Q, et al. Asthma-Related health care resource use among asthmatic children with and without concomitant allergic rhinitis. Pediatrics 2005;115:129-34.

28 Ng'ang'a LW, Odhiambo JA, Mungai MW, Gicheha C, et al. Prevalence of exercise induced bronchospasm in Kenyan school children: an urban-rural comparison. Thorax 1998;53:919-26.

29 Addo Yobo EO, Custovic A, Taggart SC, et al. Exercise induced bronchospasm in Ghana: differences in prevalence between urban and rural schoolchildren. Thorax 1997;52:161-5.
30 Olaniyan T, Dalvie MA, Röösli M, et al. Asthma-Related outcomes associated with indoor air pollutants among schoolchildren from four informal settlements in two municipalities in the Western Cape Province of South Africa. Indoor Air 2019;29:89-100.

31 Torres-Duque C, Maldonado D, Pérez-Padilla R, et al. Biomass fuels and respiratory diseases: a review of the evidence. Proc Am Thorac Soc 2008;5:577-90.

32 Green RJ, Greenblatt MM, Plit M, et al. Asthma management and perceptions in rural South Africa. Ann Allergy Asthma Immunol 2001;86:343-7.

33 Mosler G, Oyenuga V, Addo-Yobo E, et al. Achieving control of asthma in children in Africa (Acacia): protocol of an observational study of children's lung health in six sub-Saharan African countries. BMJ Open 2020;10:e035885.

34 Rodriguez A, Vaca MG, Chico ME, et al. Rural to urban migration is associated with increased prevalence of childhood wheeze in a Latin-American City. BMJ Open Respir Res 2017;4:e000205.

35 Ponte EV, Lima A, Almeida PCA, et al. Rural to urban migration contributes to the high burden of asthma in the urban area. Clin Respir J 2019;13:560-6.

36 Amin S, Soliman M, Mclvor A, et al. Understanding patient perspectives on medication adherence in asthma: a targeted review of qualitative studies. Patient Prefer Adherence 2020;14:541-51.

37 Semenya SS, Maroyi A. Plants used by Bapedi traditional healers to treat asthma and related symptoms in Limpopo Province, South Africa. Evid Based Complement Alternat Med 2018;2018:1-33.

38 Vernon MK, Wiklund I, Bell JA, et al. What do we know about asthma triggers? A review of the literature. J Asthma 2012;49:991-8.

39 Zar HJ, Asmus MJ, Weinberg EG. A 500-ml plastic bottle: an effective spacer for children with asthma. Pediatr Allergy Immunol 2002;13:217-22

40 Ndarukwa P, Chimbari MJ, Sibanda EN. Development of a framework for increasing asthma awareness in Chitungwiza, Zimbabwe. Asthma Res Pract 2019;5:4.

41 Mash B, Rhode H, Pather M, et al. Quality of asthma care: Western Cape Province, South Africa. S Afr Med J 2009;99:892-6. 